\title{
Sudden versus gradual withdrawal of sotalol in ambulant patients with ischaemic heart disease
}

\author{
A HENDERSON, J ERRINGTON \\ From the Department of Cardiology, Freeman Hospital, Newcastle upon Tyme
}

SUMMARY One hundred and six patients with ischaemic heart disease on chronic treatment with sotalol or placebo were asked to discontinue the drugs gradually or abruptly. Even though the patients were fully active at home there was a very low incidence of major cardiac events but a significant worsening of anginal symptoms in patients previously taking sotalol. The rate at which the sotalol was discontinued did not appear to be important.

Concern about a beta blocker withdrawal rebound phenomenon continues. Numerous case reports ${ }^{1-9}$ of major cardiac events occurring after the sudden discontinuation of these drugs in patients with ischaemic heart disease seem to support the idea of rebound, but in a condition as unpredictable as coronary heart disease the value of this evidence is open to question. Four retrospective studies ${ }^{10-13}$ failed to confirm clinically significant rebound and a recent prospective study of patients with angina admitted to hospital ${ }^{14}$ showed a low incidence of cardiac events after the sudden discontinuation of propranolol.

In this study an attempt has been made to evaluate the risk of sudden withdrawal of sotalol in patients with coronary heart disease who were all fully ambulant at home.

\section{Subjects and method}

The patients formed part of a larger sotalol secondary prevention trial, the details of which can be found elsewhere. ${ }^{15}$ All had had a definite acute myocardial infarction and had been randomly allocated on a 3:2 basis within 14 days of infarction to sotalol $(320 \mathrm{mg}$ daily) or placebo. The first 106 patients to complete 12 months follow-up were enrolled in this study, and were randomly allocated on a 1:1 basis to either gradual (over two weeks) or abrupt (immediate discontinuation) withdrawal of the trial drug. The groups were well matched with regard to age, sex, pre-existing hypertension, pre-existing angina, smoking habits, and site of infarction. All patients were fully ambulant at home and 38 were working. On entry into this study renal function (as reflected by blood urea) and nitrate therapy were recorded. Four weeks after stopping the trial drug the patients were assessed by a doctor blind to both randomisations. During the 12 month period of treatment and the one month period after drug withdrawal all antianginal agents except nitrates were prohibited.

\section{Results}

The distribution of patients was: 44 on placebo; 31 gradual withdrawal from sotalol, and 31 abrupt withdrawal from sotalol.

\section{MAJOR CARDIAC EVENTS}

This heading includes sudden death, major arrhythmias, fatal and non-fatal myocardial infarction, and severe angina requiring hospital admission.

The only major cardiac event was a non-fatal myocardial infarction complicated by ventricular fibrillation in a patient who had stopped sotalol after gradual withdrawal.

\section{ANGINA (Table)}

In the placebo group 17 patients experienced angina while taking the trial drug. Three felt the angina to be worse after stopping the drug while one felt improved. None developed new onset angina or had a recurrence of previous angina. In the group who gradually stopped sotalol 12 had angina while taking the drug and all continued to have it afterwards. Six felt unchanged after stopping but six felt worsening of the angina though none required admission to hospital. One developed new onset angina and two had a recurrence of previous angina.

In the group who suddenly stopped sotalol 16 had angina while taking the drug and all experienced 
Table Effect of withdrawing treatment on angina

\begin{tabular}{llll}
\hline & Placebo (44) & $\begin{array}{c}\text { Sotalol (gradual } \\
\text { withdrawal) (31) }\end{array}$ & $\begin{array}{l}\text { Sotalol (abrupt } \\
\text { withdrawal) }(31)\end{array}$ \\
\hline $\begin{array}{l}\text { Angina during } \\
\text { treatment }\end{array}$ & $17(39 \%)$ & $12(39 \%)$ & $16(52 \%)$ \\
$\begin{array}{c}\text { Angina worse after } \\
\text { stopping treatment }\end{array}$ & $3(7 \%)$ & $6(19 \%)$ & $7(23 \%)$ \\
$\begin{array}{c}\text { Angina unchanged } \\
\text { after stopping } \\
\text { treatment }\end{array}$ & $13(30 \%)$ & $6(19 \%)$ & $8(25 \%)$ \\
$\begin{array}{c}\text { Angina improved } \\
\text { after stopping } \\
\text { treatment }\end{array}$ & $1(2 \%)$ & 0 & $1(3 \%)$ \\
$\begin{array}{c}\text { New onset angina } \\
\text { after stopping } \\
\text { treatment }\end{array}$ & 0 & $1(3 \%)$ & $2(6 \%)$ \\
$\begin{array}{c}\text { Recurrence of angina } \\
\text { after stopping } \\
\text { treatment }\end{array}$ & 0 & $2(6 \%)$ & 0 \\
\hline
\end{tabular}

angina after stopping. Eight felt unchanged, seven had worsening of the angina, and one felt improved. Two patients developed new onset angina but none had a recurrence of previous angina. None required hospital admission.

\section{PALPITATION}

Several patients reported an unusual awareness of their heart beat during the study. In the placebo group three had palpitation while on treatment and all continued to experience it after stopping the drug. One developed palpitation for the first time after discontinuation of the trial drug. In the sotalol group on gradual withdrawal none had palpitation on treatment but four developed it after stopping, while in the abrupt withdrawal group one had palpitation on treatment and continued to suffer it after stopping, while four developed new onset palpitation after stopping.

\section{GENERAL WELL-BEING}

In the placebo group, three patients felt better and four felt worse after stopping treatment, while in the sotalol groups two patients felt better and two felt worse after gradual withdrawal and one felt worse after abrupt withdrawal.

\section{HEART RATE}

The mean heart rate of the placebo group on treatment was 69 beats/minute and after stopping 72 beats/ minute. In the sotalol group on treatment the mean heart rate was 57 beats/minute which was significantly slower than the placebo group $(p<0.01)$. The mean heart rate after stopping sotalol rose to 81 beats/minute in the gradual withdrawal group and to 82 beats/minute in the abrupt withdrawal group which was significantly faster than while on sotalol $(p<0.01)$ and compared with patients who discontinued placebo $(\mathrm{p}<0 \cdot 01)$.

\section{BLOOD PRESSURE}

The mean blood pressure in the placebo group was
$150 / 90 \mathrm{mmHg}$ on treatment and $152 / 92 \mathrm{mmHg}$ after stopping. The mean blood pressure in the sotalol group was $145 / 89 \mathrm{mmHg}$, and after stopping the drug $145 / 89$ $\mathrm{mmHg}$ after gradual withdrawal and $146 / 89 \mathrm{mmHg}$ following abrupt withdrawal. Eleven patients in the sotalol group had a history of hypertension and of these only two showed a large rise in blood pressure after stopping the drug. The patient who had the largest rise from $140 / 100$ to $180 / 120 \mathrm{mmHg}$ suffered the only myocardial infarction in the series.

\section{RENAL FUNCTION}

There was no difference in renal function as judged by blood urea measured immediately before discontinuing the trial drug.

Mean Urea. (a) Placebo group $6.1 \mathrm{mmol} / \mathrm{l}$ (range 2.68.6); (b) sotalol (gradual withdrawal) $5.4 \mathrm{mmol} / \mathrm{l}$ (range 3.1-9.4); (c) sotalol (abrupt withdrawal) $5 \cdot 4 \mathrm{mmol} / \mathrm{l}$ (range 2:8-9.5).

\section{NITRATE TREATMENT}

Patients were allowed glyceryl trinitrate as required. At the start of this study only six were using long acting nitrates: one in the placebo group, two gradually stopping sotalol, and three abruptly stopping sotalol. None was using any other antianginal drug.

\section{Discussion}

It is important to distinguish between the effects of sotalol withdrawal compared with placebo from the effects of withdrawing sotalol gradually or suddenly. As sotalol is an effective antianginal drug, one might anticipate worsening of angina after its withdrawal. This is the case in our study where only $7 \%$ of the placebo group experienced worsening of angina after stopping the drug compared with $21 \%$ of patients who stopped sotalol (SE 6.4). There was no difference in the incidence of worsening angina between the patients suddenly stopping (23\%) and those gradually stopping sotalol (19\%). New onset angina was uncommon but was confined to patients discontinuing sotalol. Though this might be a rebound phenomenon a likely explanation is progression of the coronary heart disease, the clinical expression of which had been prevented by sotalol. Similarly the reappearance of previous angina may reflect simply the removal of effective suppressive treatment. The rate of sotalol withdrawal did not influence the incidence of new onset or recurrent angina.

The incidence of major cardiac events was very low even in patients who were fully active at home or at work. The single non-fatal myocardial infarction occurred in a patient who had stopped sotalol after gradual withdrawal. This individual was previously 
hypertensive and showed a large increase in blood pressure after stopping sotalol. This reaction, however, appeared to be uncommon and occurred in only two of the 11 hypertensive patients treated with sotalol.

Patients taking sotalol had a significant bradycardia, and interestingly after stopping the drug appeared to have a slight overshoot in their mean heart rate which exceeded that of the placebo group ( 82 beats/minute and 72 beats/minute, respectively). The rate of sotalol withdrawal did not appear to influence the mean heart rate. Whether this represents a change in catecholamine levels or increased sensitivity of the beta receptors as suggested by Boudoulas et al. ${ }^{16}$ is not clear. Whatever the mechanism underlying the overswing, it appears to be of no clinical significance. With regard to minor symptoms there was no real difference in the general well-being between patients in any of the groups after withdrawal of treatment except for palpitation which was experienced more frequently by those discontinuing sotalol.

This study shows that sotalol can be discontinued in patients with ischaemic heart disease who are fully active at home without major risk of a cardiac catastrophe. It is however important to anticipate worsening of angina in some patients simply on the basis of withdrawing an effective antianginal agent. Whether sotalol was discontinued gradually or suddenly appeared unimportant. Before concluding that beta blockers in general can be safely stopped in a sudden fashion, however, one must consider the half life of the particular drug. Sotalol has a long half life (seven to 18 hours) so even sudden discontinuation of treatment may still allow a relatively gradual reduction in beta blockade compared, for example, with the discontinuation of a short acting drug such as propranolol. Though the results of this study must be interpreted in the context of a long half life beta blocker the precise clinical importance of half life duration remains unclear. The study of Myers et al. ${ }^{14}$ of propranolol withdrawal in patients in hospital suggests even short half life beta blockers can be suddenly stopped without major risk.

\section{References}

1 Olson $\mathrm{HG}$, Miller RR, Amsterdam EA, Wood $M$, Brocchini R, Mason D. The propranolol withdrawal rebound phenomenon: acute and catastrophic exacer- bation of symptoms and death following the abrupt cessation of large doses of propranolol in coronary artery disease (abstract). Am $\mathcal{F}$ Cardiol 1975; 35: 162.

2 Diaz RG, Somberg J, Freeman E, Levitt B. Myocardial infarction after propranolol withdrawal. Am Heart $\mathcal{~ . ~ 1 9 7 4 ; ~}$ 88: 257-8.

3 Diaz RG, Somberg JC, Freeman E, Levitt B. Withdrawal of propranolol and myocardial infarction (letter). Lancet 1973; i: 1068.

4 Mizgala HF, Counsell J. Acute coronary syndromes following abrupt cessation of oral propranolol therapy. Can Med Assoc F 1976; 114: 1123-6.

5 Williams LC, Turney JH, Parsons V. Beta blocker withdrawal syndrome (letter). Lancet 1979; i: 494-5.

6 Meinertz T, Just H, Kasper W, Kersting F, Breuing KH. Beta blocker withdrawal syndrome (letter). Lancet 1979; i: 270.

7 Miller RR, Olson HG, Amsterdam EA, Mason DT. Propranolol withdrawal rebound phenomenon. $N$ Engl $\mathcal{F}$ Med 1975; 293: 416-8.

8 Slome R. Withdrawal of propranolol and myocardial infarction (letter). Lancet 1973; i: 156.

9 Alderman EL, Coltart DJ, Wettach GE, Harrison DC. Coronary artery syndrome after sudden propranolol withdrawal. Ann Intern Med 1974; 81: 625-7.

10 Myers MG, Wisenberg G. Sudden withdrawal of propranolol in patients with angina pectoris. Chest 1977; 71: 24-6.

11 Raabe DS, Meengs WL, Crary JL, Sorkin RP, Gregory JM, Walton JA. Risk of suddenly discontinuing propranolol therapy before coronary arteriography (abstract). Circulation 1975; 52, suppl ii: 12.

12 Shiroff RA, Mathis J, Hayes AN, et al. The propranolol rebound phenomenon. Fact or fiction? Clin Res 1976; 24: $622 \mathrm{~A}$.

13 Shiroff R, Mathis J, Zelis R, et al. Propranolol rebounda retrospective study. Am F Cardiol 1978; 41: 778-80.

14 Myers MG, Freeman MR, Juma ZA, Wisenberg G. Propranolot withdrawal in angina pectoris. A prospective study. Am Heart $\mathcal{F}$ 1979; 97: 298-302.

15 Julian DG, Prescott RJ, Jackson FS, Szekely P. Controlled trial of Sotalol for one year after myocardial infarction. Lancet 1982; i: 1142-7.

16 Boudoulas H, Lewis RP, Kates RE, Dalamangas G. Hypersensitivity to adrenergic stimulation after propranolol withdrawal in normal subjects. Ann Intern Med 1979; 87: 433-6.

Requests for reprints to Dr J Errington, Department of Cardiology, Freeman Hospital, Freeman Road, Newcastle upon Tyne NE7 7DN. 